\title{
Interactions Between Ionic Liquid (ALiCY) and TBP and their Use in Hydrometallurgy for Extracting $\mathrm{Co}$ (II) and $\mathrm{Ni}(\mathrm{II})$
}

\author{
Thanh Tuan Tran and Man Seung Lee* \\ Department of Advanced Materials Science \& Engineering, Institute of Rare Metal, Mokpo National University, \\ Chonnam 58554, Republic of Korea
}

\begin{abstract}
Ionic liquids have emerged in hydrometallurgy as potential extractants for metals. In this work, the interactions of ALiCY $\left(\mathrm{R}_{4} \mathrm{~N}^{+} \mathrm{A}^{-}\right)$synthesized by Aliquat336 and Cyanex272, and a mixture of ALiCY and TBP, were analyzed using extraction data and FT-IR spectroscopy. Co(II) and Ni(II) were extracted from two $\mathrm{HCl}$ concentrations $\left(1.0 \times 10^{-4}\right.$ and $\left.6.8 \mathrm{~mol} \mathrm{~L}^{-1}\right)$ using ALiCY and its mixture with TBP. The extraction results indicated that $\mathrm{ALiCY}$ has a dual function, as a cationic extractant at low $\mathrm{HCl}$ concentration and an anionic extractant at high $\mathrm{HCl}$ concentration depending on the types of metal complexes. The addition of TBP to ALiCY had a negative effect on the extraction of $\mathrm{Co}(\mathrm{II})$ from the $6.8 \mathrm{~mol} \mathrm{~L}^{-1} \mathrm{HCl}$, while the effect was negligible from the $1.010^{-4} \mathrm{~mol} \mathrm{~L}^{-1} \mathrm{HCl}$. The solvation of $\mathrm{R}_{4} \mathrm{~N}^{+}$by TBP significantly affected the extraction behavior of ALiCY for metal ions. The formation of hydrogen bonding between TBP and Cyanex272 was verified. These findings shed light on the behavior and interaction occurring between bif-ILs and solvating extractants for the extraction of metals in acidic media.
\end{abstract}

(Received January 20, 2020; Accepted April 29, 2020)

Keywords: ionic liquids, solvent extraction, hydrometallurgy, aliquat336

\section{Introduction}

Liquid-liquid extraction is a chemical technique which utilizes the distribution of solutes between two immiscible liquid phases [1]. The technique is employed in hydrometallurgy for the extraction and purification of metals. However, choosing suitable extractants that have both good performance and environmental friendliness is a challenging task.

Today, commercial extractants and their mixtures are widely employed to separate metal ions from diverse aqueous media. In metal processing industries, when the metal ions exist in cationic form in aqueous solution, organophosphorous acids are frequently employed, such as Cyanex272 (bis(2,4,4-trimethylpentyl)phosphinic acid), D2EHPA (di-(2-ethylhexyl)phosphoric acid), Cyanex301 (bis(2,4,4trimethylpentyl)dithiophosphinic acid) [2-4]. However, the use of these acidic extractants to extract metal ions from

- Thanh Tuan Tran: 박사과정, 이만승: 교수

*Corresponding Author: Man Seung Lee

[Tel: +82-61-450-2492, E-mail: mslee@mokpo.ac.kr]

Copyright (c) The Korean Institute of Metals and Materials weak acidic solutions results in a decrease in equilibrium $\mathrm{pH}$, which reduces the effectiveness of the extraction. Saponification of these acidic extractants by $\mathrm{NH}_{3}$ and $\mathrm{NaOH}$ generates effluents which contain the corresponding ammonia-nitrogen and $\mathrm{Na}^{+}$, leading to environmental issues $[5,6]$. Although neutral extractants avoid the disadvantages of acidic extractants, their selectivity for metal extraction is lower than that of organophosphorus acids [7]. Thus, a new extraction system is needed to circumvent the disadvantages of the organophosphorous acids in metal processing.

Ionic liquids (ILs) are organic salts with a melting point below $100{ }^{\circ} \mathrm{C}$. ILs have specific properties including thermal stability, low flammability and negligible vapor pressure [8]. In particular, their physicochemical properties can be controlled by changing discrete cations and anions, which gives them more flexibility and a wider selection of properties [9]. For instance, changing the viscosity or enhancing the ionic exchange characteristics of ILs can be performed by either increasing or decreasing alkyl groups in the molecular components, or by replacing other ionic components.

The use of imidazolium, ammonium, or phosphonium ILs 
for the separation of metal ions has recently been reported [10-13]. However, the use of hydrophilic ILs often results in the loss of IL components during the extraction, which requires regeneration of the ILs [14]. Moreover, ILs containing fluoride can also be hydrolyzed, producing toxic and corrosive chemicals such as $\mathrm{HF}, \mathrm{POF}_{3}, \mathrm{H}_{2} \mathrm{PO}_{3} \mathrm{~F}$, and $\mathrm{HPO}_{2} \mathrm{~F}_{2}[15,16]$. Therefore, the ILs most desirable for extracting metals are composed of non-fluorinated anions and functional cations, such as tricaprylmethylammonium chloride (Aliquat 336, [A336][Cl]) and tri(hexyl)tetradecylphosphonium chloride (Cysphos IL 101) [17, 18]. Many bi-functional ionic liquids (bif-IL) have been developed based on Aliquat336 or Cysphos IL 101, including [A336][P204], [A336][P507], [A336][C272], [A336][C302], [A366][CA-12], [A336][CA100], TOMAS, Cysphos 104 and Cysphos 167. These bif-ILs can extract metal ions as well as hydrogen ions, which is of great importance for controlling the equilibrium $\mathrm{pH}$ [19-25]. However, these bif-ILs are often very viscous and thus require the use of diluents or other extractants as a modifier.

Mixtures of solvating extractants such as TBP or TOPO and other extractants have been employed for the synergistic extraction of metal ions and to prevent the formation of a third phase [26-28]. Adding solvating extractants to ionic liquids can also result in synergisms which enhance metal extraction. To the best of our knowledge, the interaction between bif-IL and neutral extractants has not yet been analyzed.

In this work a bif-IL synthesized using Aliquat336 and Cyanex272 was selected, and the effect of adding TBP to this bif-IL was investigated. The interactions between the mixtures were analyzed by FT-IR. Then, the extraction behavior of $\mathrm{Co}$ (II) and $\mathrm{Ni}(\mathrm{II})$ in $\mathrm{HCl}$ solutions with bif-IL and its mixture with TBP was investigated.

Since the concentration of $\mathrm{HCl}$ acid significantly affects the formation of chloride complexes of metal ions, the extraction behavior of the two metal ions using these extractants was investigated in strong and weak acidic media, corresponding to $1.0 \times 10^{-4}$ and $6.8 \mathrm{~mol} \cdot \mathrm{L}^{-1} \mathrm{HCl}$. The extracted metal species in the loaded organic phase were identified by UV/VIS spectra. Based on these results, the role of TBP in the extraction of $\mathrm{Co}$ (II) and $\mathrm{Ni}$ (II) by the bif-IL is discussed.

\section{Experimental}

\subsection{Reagents and Chemicals}

The extractants such as Aliquat336 (N-Methyl-N, N, Ntrioctylammonium chloride, BASF Co., 93\%), Cyanex 272 (bis(2,4,4-trimethylpentyl)phosphinic acid, Cytec Inc., 85\%) and TBP (tributylphosphate) were used without any purification. The structure and properties of these extractants are presented in Table 1. Kerosene (Samchun Pure Chemical Co.) was used as a diluent and all the other chemicals used were of analytical grade.

The synthetic solutions of $\mathrm{Co}$ (II) and Ni (II) were prepared by dissolving appropriate amounts of $\mathrm{CoCl}_{2} \cdot 6 \mathrm{H}_{2} \mathrm{O}$ (Junsei Chemical Co., $\geq 97 \%$ ) and $\mathrm{NiCl}_{2} \cdot 6 \mathrm{H}_{2} \mathrm{O}$ (Yakuri Pure Chemical Co., Japan, $\geq 96 \%$ ) in acid solutions. The concentration of metal ions was approximately $500 \mathrm{mg} \cdot \mathrm{L}^{-1}$. The acidity of the solution was adjusted by adding doubly distilled water to concentrated $\mathrm{HCl}$ (Daejung Co., 35\%).

ALiCY (N-Methyl-N, N, N-trioctylammonium bis(2,4,4trimethylpentyl)phosphinate, $\mathrm{R}_{4} \mathrm{NA}$ ) was prepared by mixing an equimolar concentration of Aliquat336 $\left(\mathrm{R}_{4} \mathrm{NCl}\right)$ and Cyanex272 (HA) in kerosene according to the method reported in the paper [29].

\subsection{Extraction procedure}

The extraction experiments were carried out by mixing equal volumes of aqueous and organic phase (each $15 \mathrm{~mL}$ ) in a screw cap bottle for 30 minutes using a Burrell wrist action shaker (model 75, USA) at ambient temperature $\left(22 \pm 1{ }^{\circ} \mathrm{C}\right)$. The shaken solutions were allowed to stand in a glass separatory funnel for phase separation. The concentration of hydrogen ions in the aqueous phases before and after extraction was determined by Orion Star thermal scientific pH meter (model A221, USA) and the volumetric titration method [30].

\subsection{Analytical methods}

Fourier transform infrared spectrometers (FT-IR-Vertex 80 $\mathrm{V}$, Bruker, Germany) were employed to analyze the formation of ALiCY, and interactions between individual extractants in the mixtures before and after extraction. The infrared spectra were taken in the range of $4000-550 \mathrm{~cm}^{-1}$. However, the spectra were mainly analyzed in the range of 
Table 1. Properties and chemical structures of the extractants

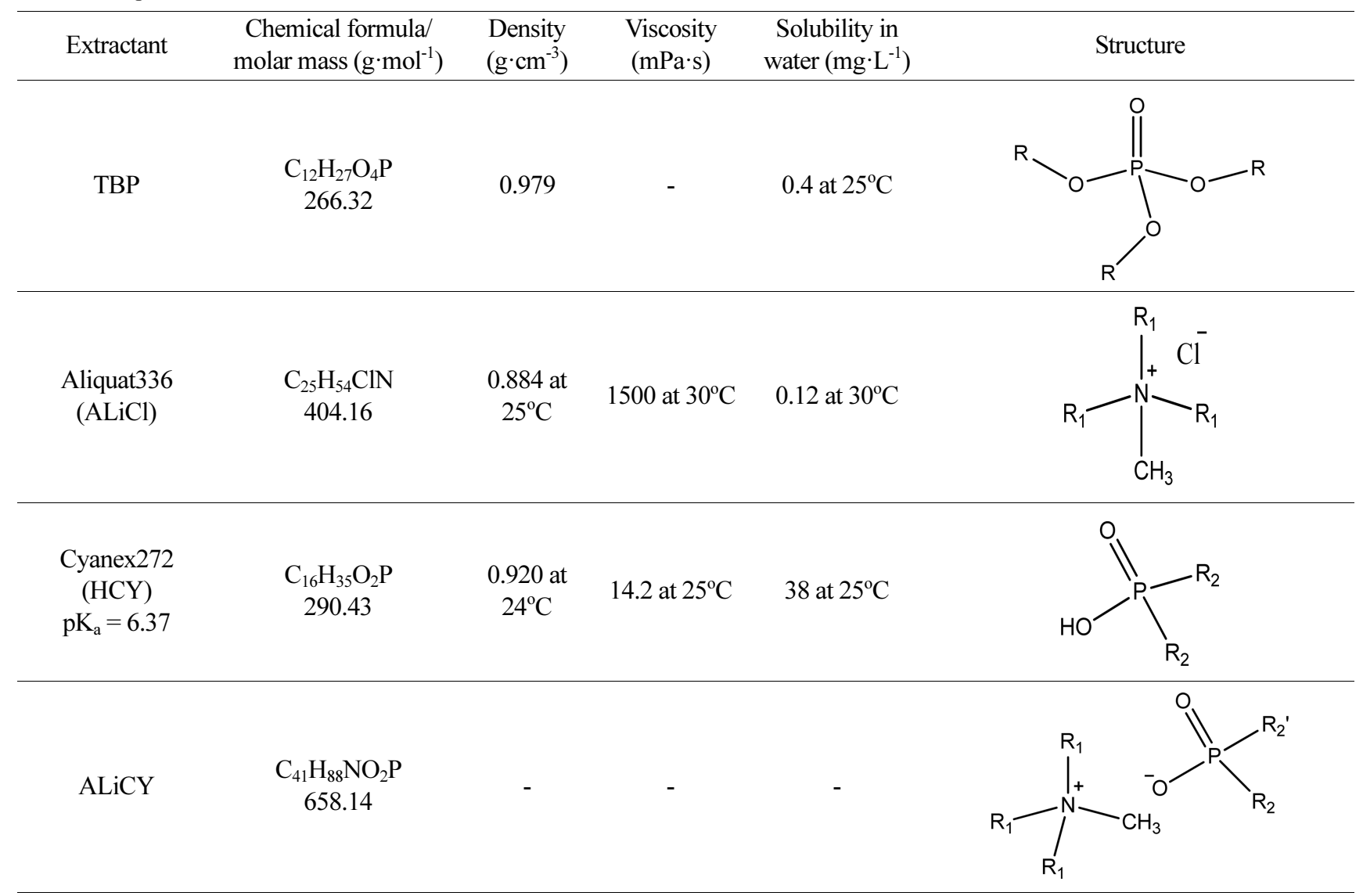

Where $\mathrm{R}, \mathrm{R}_{1}, \mathrm{R}_{2}$ denote the butyl, octyl-, and 2,4,4-trimethylpentyl groups, respectively.

$1600-600 \mathrm{~cm}^{-1}$, where most of the significant changes occurred. The loaded organic phases were analyzed spectrophotometrically using UV/VIS (UV-1800, Shimadzu, Japan).

The concentration of nickel and cobalt ions in the aqueous phases before and after extraction was determined by ICPOES (Inductively coupled plasma-optical emission spectrometry, Spectro Arcos). Extraction percentage (\%E) was calculated from the concentration of metal ions in the aqueous phases before $[\mathrm{M}]_{\mathrm{i}}$ and after $[\mathrm{M}]^{*}{ }_{(\mathrm{aq})}$ extraction: $\% \mathrm{E}$ $=\left(\frac{\left([M]_{i}-[M]_{(a q)}^{*}\right)}{[M]_{i}}\right) \times 100$, assuming that there was no change in the volume of the two phases after extraction.

The distribution ratio $\mathrm{D}$, was calculated from the relation: $D=\left(\frac{\left([M]_{i}-[M]_{(a q)}^{*}\right)}{[M]_{(a q)}^{*}}\right)$

The separation factor, $\mathrm{SF}_{\mathrm{Co} / \mathrm{Ni}}$, between $\mathrm{Co}(\mathrm{II})$ and $\mathrm{Ni}(\mathrm{II})$ was defined by the following equation: $S F=\frac{D_{C o}}{D_{N i}}$

\section{Results and Discussion}

\subsection{Analysis of the formation of ALiCY by} FT-IR

In order to identify the formation of bif-IL, the FT-IR spectra of ALiCY ( $\left.\mathrm{R}_{4} \mathrm{NA}\right)$ was compared with that of Aliquat336 (ALiCl, $\mathrm{R}_{4} \mathrm{NCl}$ ) and Cyanex272 (HCY, HA). The concentration of the analysts was fixed at $0.1 \mathrm{~mol} \cdot \mathrm{L}^{-1}$. The frequencies of the characteristic stretching vibrational bands of these extractants in kerosene are presented in Fig. 1 and Table 2.

It has been reported that the -OH stretching vibration bands of Cyanex272 in nonpolar diluents would be present in the region 2700-1700 $\mathrm{cm}^{-1}$ because of intermolecular hydrogen bonding in the dimeric form [31]. However, this band was not observed in any of the spectra in the present work, which 


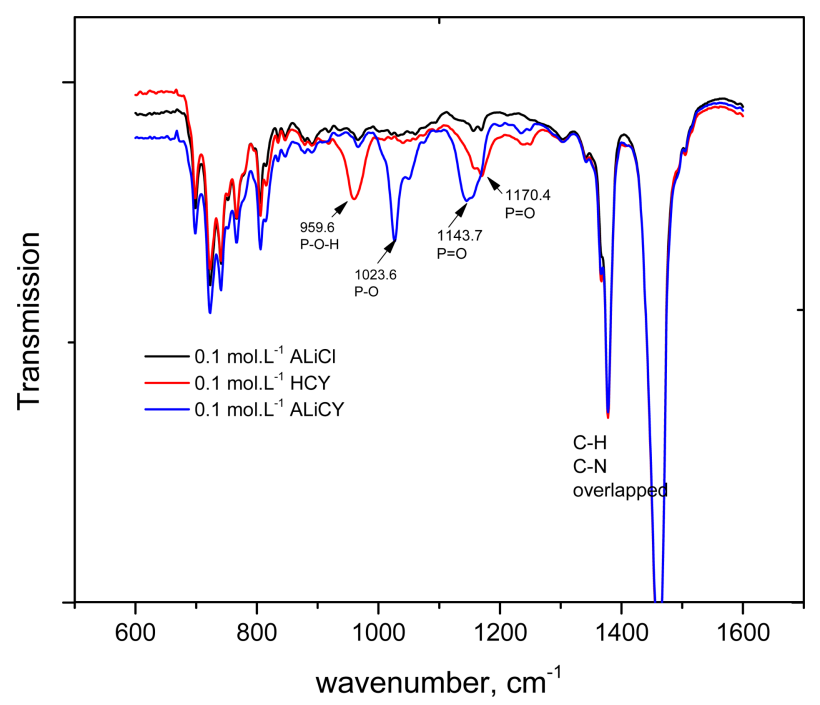

Fig. 1. FT-IR of Aliquat336 (ALiCl), Cyanex272 (HCY) and ALiCY in kerosene. Concentration of extractants was fixed 0.1 $\mathrm{mol} \cdot \mathrm{L}^{-1}$

Table 2. Frequencies of characteristic vibrational bands of individual extractants in kerosene.

\begin{tabular}{cccc} 
Extractants & $\mathrm{P}=\mathrm{O}$ & $\mathrm{P}-\mathrm{O}-\mathrm{H}$ or P-O & $\begin{array}{c}\mathrm{C}-\mathrm{N} \text { and C-H } \\
\text { overlapped }\end{array}$ \\
\cline { 1 - 3 } $\mathrm{ALiCl}$ & - & - & $\begin{array}{c}1378.5 \text { and } \\
1459.2\end{array}$ \\
\cline { 1 - 3 } $\mathrm{HCY}$ & 1170.4 & 959.6 & \\
\hline ALiCY & 1143.7 & 1023.6 & \\
\hline
\end{tabular}

matches other reported results [32]. The characteristic stretching vibrational bands of Cyanex 272 for $\mathrm{P}=\mathrm{O}$ and $\mathrm{P}-\mathrm{O}$ groups were at $1170.4 \mathrm{~cm}^{-1}$ and at $959.6 \mathrm{~cm}^{-1}$. The characteristic peaks of C-N and C-H in Aliquat 336 at 1378.5 and $1459.2 \mathrm{~cm}^{-1}$ were overlapped by the $\mathrm{C}-\mathrm{H}$ stretching vibrations of kerosene. Therefore, the spectra were analyzed to detect any change in the characteristic bands of $\mathrm{P}=\mathrm{O}$ and P-O groups.

Comparing the spectra of ALiCY to that of Cyanex272, there was a significant shift in the positions of the characteristic stretching vibrational bands of the $\mathrm{P}=\mathrm{O}$ and $\mathrm{P}$ $\mathrm{O}$ groups, namely from $1170.4 \mathrm{~cm}^{-1}(\mathrm{P}=\mathrm{O}$ group) and 959.6 $\mathrm{cm}^{-1}$ (P-O group) of Cyanex272 to $1143.7 \mathrm{~cm}^{-1}$ ( $\mathrm{P}=\mathrm{O}$ group) and $1023.6 \mathrm{~cm}^{-1}$ (P-O groups) of ALiCY, respectively. Besides that, the increasing intensity of the peaks, which could be due to the interaction between Aliquat336 cation $\left(\mathrm{R}_{4} \mathrm{~N}^{+}\right)$and Cyanex272 anion $\left(\mathrm{A}^{-}\right)$, also indicated the successful synthesis of bif-IL.

3.2 Effect of hydrochloric acid concentration on the $\mathrm{Co}(\mathrm{II})$ and $\mathrm{Ni}(\mathrm{II})$ extraction by ALiCY

The extraction of $\mathrm{Co}(\mathrm{II})$ and $\mathrm{Ni}(\mathrm{II})$ by $0.1 \mathrm{~mol} \cdot \mathrm{L}^{-1} \mathrm{ALiCY}$ was investigated using two hydrochloric acid solutions, of $1.0 \times 10^{-4}$ and $6.8 \mathrm{~mol} \cdot \mathrm{L}^{-1}$. In these experiments, the concentration of $\mathrm{Co}$ (II) and $\mathrm{Ni}(\mathrm{II})$ was fixed at $500 \mathrm{mg} \cdot \mathrm{L}^{-1}$. The extraction percentages of $\mathrm{Co}$ (II) and $\mathrm{Ni}$ (II) in the $1.0 \times 10^{-4}$ $\mathrm{mol} \cdot \mathrm{L}^{-1} \mathrm{HCl}$ were 57.4 and $36.8 \%$, while that of $\mathrm{Co}$ (II) at 6.8 $\mathrm{mol} \cdot \mathrm{L}^{-1} \mathrm{HCl}$ was $51.1 \%$ and no $\mathrm{Ni}(\mathrm{II})$ was extracted at all.

When the hydrochloric acid concentration is $1.0 \times 10^{-4}$ $\mathrm{mol} \cdot \mathrm{L}^{-1}$, both $\mathrm{Co}(\mathrm{II})$ and $\mathrm{Ni}(\mathrm{II})$ exist in cationic forms (e.g $\left.\mathrm{Co}\left(\mathrm{H}_{2} \mathrm{O}\right)_{6}\right]^{2+}, \quad\left[\mathrm{Co}\left(\mathrm{H}_{2} \mathrm{O}\right)_{5} \mathrm{Cl}\right]^{+}$, and $\left.\left[\mathrm{Ni}\left(\mathrm{H}_{2} \mathrm{O}\right)_{6}\right]^{2+}\right)$. Unlike $\mathrm{Ni}(\mathrm{II}), \mathrm{Co}(\mathrm{II})$ has a strong tendency to form complexes with chloride ions. Cobalt ions in the concentrated $\mathrm{HCl}(6.8$ $\mathrm{mol} \cdot \mathrm{L}^{-1}$ ) favor the formation of chlorocomplexes with a tetrahedral configuration, like $\mathrm{CoCl}_{3}^{-}$and $\mathrm{CoCl}_{4}{ }^{2-}$, while nickel ions tend to exhibit an octahedral form (e.g., $\left.\mathrm{Ni}\left(\mathrm{H}_{2} \mathrm{O}\right)_{5} \mathrm{Cl}^{+}, \mathrm{Ni}\left(\mathrm{H}_{2} \mathrm{O}\right)_{4} \mathrm{Cl}_{2}\right)$ [13]. Moreover, it has been reported that the cation of Aliquat336 forms $\mathrm{R}_{4} \mathrm{~N}^{+}\left[\mathrm{HCoCl}_{4}\right]^{-}$ species when the $\mathrm{HCl}$ concentration is higher than $5 \mathrm{~mol} \cdot \mathrm{L}^{-1}$ $[33,34]$. The fact that no nickel was extracted from the 6.8 $\mathrm{mol} \cdot \mathrm{L}^{-1} \mathrm{HCl}$ solution indicates that the interaction between nickel ions and the anion of Cyanex 272 under this condition is weak, and thus ALiCY extracted only anionic complexes of $\mathrm{Co}(\mathrm{II})$. These results agree well with the reported data [13]. In addition, the extraction of hydrogen ions by ALiCY was also observed. The variation in the concentration of hydrogen ions is presented in Table 3.

Accordingly, the solvent extraction of $\mathrm{Co}(\mathrm{II})$ and $\mathrm{Ni}$ (II) by ALiCY at the two $\mathrm{HCl}$ concentrations could be represented as:

In the $1.0 \times 10^{-4} \mathrm{~mol} \cdot \mathrm{L}^{-1} \mathrm{HCl}$ concentration:

$$
\mathrm{MeCl}_{2 \text { aq }}+2 \mathrm{R}_{4} \mathrm{NA}_{\text {org }}=2 \mathrm{R}_{4} \mathrm{NCl}_{\text {org }}+\mathrm{MeA}_{2} \text { org }
$$

Table 3. The concentration of hydrogen ion in the aqueous phase after the extraction with the organic phase

\begin{tabular}{cccccc}
\hline $\begin{array}{c}\text { The concentration of TBP } \\
\text { in the mixture }\left(\mathrm{mol} \cdot \mathrm{L}^{-1}\right)\end{array}$ & 0.00 & 0.02 & 0.05 & 0.10 & 0.20 \\
\hline $\mathrm{pH}=4\left(1.0 \times 10^{-4} \mathrm{~mol} \cdot \mathrm{L}^{-1}\right)$ & 7.35 & 7.18 & 7.22 & 7.34 & 7.34 \\
\hline$[\mathrm{HCl}]=6.8 \mathrm{~mol} \cdot \mathrm{L}^{-1}$ & 6.11 & 6.25 & 6.25 & 6.25 & 6.25 \\
\hline
\end{tabular}


where $\mathrm{Me}^{2+}$ are $\mathrm{Co}(\mathrm{II})$ and $\mathrm{Ni}(\mathrm{II})$ ions.

In the $6.8 \mathrm{~mol} \cdot \mathrm{L}^{-1} \mathrm{HCl}$ concentration:

$$
\begin{aligned}
& 2 \mathrm{H}_{\text {aq }}^{+}+\mathrm{CoCl}_{4}{ }^{2-}{ }_{\text {aq }}+\mathrm{R}_{4} \mathrm{NA}_{\text {org }}=\mathrm{R}_{4} \mathrm{NHCoCl}_{4, \mathrm{org}}+\mathrm{HA}_{\text {org }} \\
& \mathrm{H}^{+}{ }_{\mathrm{aq}}+\mathrm{CoCl}_{3 \mathrm{aq}}{ }^{-}+\mathrm{R}_{4} \mathrm{NA}_{\text {org }}=\mathrm{R}_{4} \mathrm{NCoCl}_{3, \text { org }}+\mathrm{HA}_{\text {org }} \\
& 2 \mathrm{R}_{4} \mathrm{NA}_{\text {org }}+\mathrm{H}_{\text {aq }}^{+}+\mathrm{Cl}_{\text {aq }}^{-}=\left(\mathrm{R}_{4} \mathrm{NA}\right)_{2} \cdot \mathrm{HCl}_{\text {org }}
\end{aligned}
$$

Our results clearly indicated that ALiCY can act as a cation extractant at low $\mathrm{HCl}$ concentration, while it acts as an anion extractant in strong $\mathrm{HCl}$ solution. In these experiments, the formation of a third phase was observed. Therefore, TBP was added to the ALiCY in order to prevent the formation of a third phase, and the effect of TBP addition on the extraction of $\mathrm{Co}(\mathrm{II})$ and $\mathrm{Ni}(\mathrm{II})$ was investigated.

\subsection{Effect of TBP addition to ALiCY on the} extraction of $\mathrm{Co}(\mathrm{II})$ and $\mathrm{Ni}(\mathrm{II})$

In order to investigate the effect of adding TBP to ALiCY on the extraction of $\mathrm{Co}(\mathrm{II})$ and $\mathrm{Ni}(\mathrm{II})$, the concentration of TBP in $0.1 \mathrm{~mol} \cdot \mathrm{L}^{-1}$. ALiCY was varied from 0.02 to 0.2 $\mathrm{mol} \cdot \mathrm{L}^{-1}$. These mixtures were contacted with the aqueous solutions of $1.0 \times 10^{-4}$ and $6.8 \mathrm{~mol} \cdot \mathrm{L}^{-1} \mathrm{HCl}$. The results (see Fig. 2) showed that there was no noticeable change in the extraction of the metals in the $1.0 \times 10^{-4} \mathrm{~mol} \cdot \mathrm{L}^{-1} \mathrm{HCl}$, since the TBP concentration in the mixture varied. Specifically, the extraction percentage from the mixtures was between 52.2 and $59.4 \%$ for $\mathrm{Co}$ (II) and between 30.8 and $39.1 \%$ for $\mathrm{Ni}(\mathrm{II})$. Since TBP would not extract $\mathrm{Co}(\mathrm{II})$ and $\mathrm{Ni}$ (II) from the $1.0 \times 10^{-4} \mathrm{~mol} \cdot \mathrm{L}^{-1} \mathrm{HCl}$ solution, the addition of TBP to ALiCY had little effect on the extraction characteristics of ALiCY. However, it is noteworthy that no third phase was formed in the presence of TBP in this work.

The reaction by ALiCY in $1.0 \times 10^{-4} \mathrm{~mol} \cdot \mathrm{L}^{-1} \mathrm{HCl}$ could be the same as the $\mathrm{Co}$ (II) and $\mathrm{Ni}(\mathrm{II})$ extraction. Therefore, the effect of the mixture of ALiCY and TBP on the Co(II), Ni(II) and $\mathrm{H}^{+}$extraction reaction can be proposed as:

$$
\mathrm{MeCl}_{2, \mathrm{aq}}+2 \mathrm{R}_{4} \mathrm{NA} \cdot \mathrm{TBP}_{\text {org }}=2 \mathrm{R}_{4} \mathrm{NCl} \cdot \mathrm{TBP}_{\text {org }}+\mathrm{MeA}_{2, \mathrm{org}}
$$

where $\mathrm{Me}^{2+}$ are $\mathrm{Co}^{2+}$ and $\mathrm{Ni}^{2+}$ ions.

Fig. 3 shows the effect of the addition of variable amounts of TBP to $0.1 \mathrm{M}$ ALiCY, on the extraction of $\mathrm{Co}$ (II) and $\mathrm{Ni}$ (II) from the $6.8 \mathrm{~mol} \cdot \mathrm{L}^{-1} \mathrm{HCl}$ solution. As the TBP concentration increased to $0.2 \mathrm{~mol} \cdot \mathrm{L}^{-1}$, the extraction

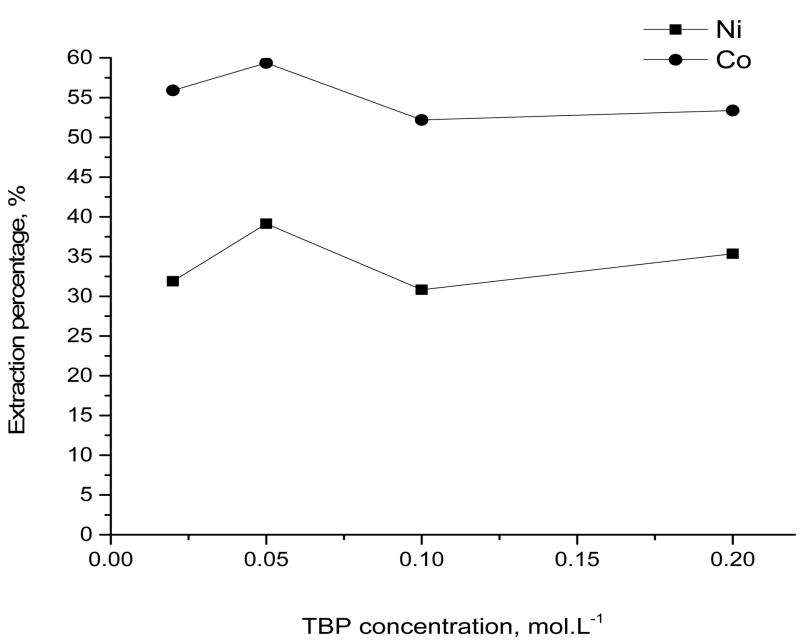

Fig. 2. Extraction percentage of $\mathrm{Co}(\mathrm{II}), \mathrm{Ni}(\mathrm{II})$ by the mixture of ALiCY and TBP at $1.0 \times 10^{-4} \mathrm{~mol} \cdot \mathrm{L}^{-1} \mathrm{HCl}$. The concentration of $\mathrm{ALiCY}$ in the mixture was fixed at $0.1 \mathrm{~mol} \cdot \mathrm{L}^{-1}$.

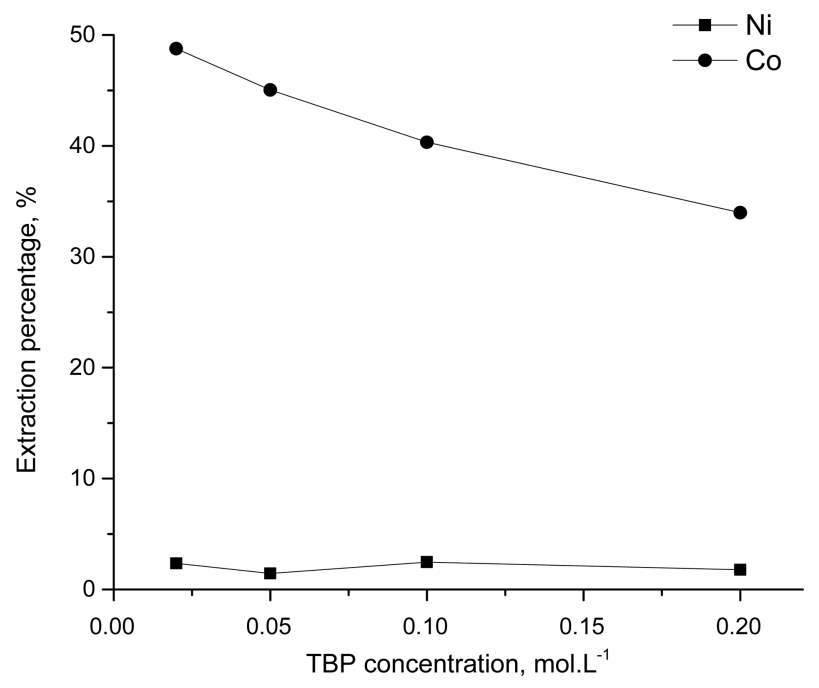

Fig. 3. Extraction percentage of $\mathrm{Co}(\mathrm{II}), \mathrm{Ni}(\mathrm{II})$ by the mixture of ALiCY and TBP at $6.8 \mathrm{~mol} \cdot \mathrm{L}^{-1} \mathrm{HCl}$. The concentration of ALiCY in the mixture was fixed at $0.1 \mathrm{~mol} \cdot \mathrm{L}^{-1}$

percentage of $\mathrm{Co}$ (II) decreased from 48.8 to $34.0 \%$, while the extraction of $\mathrm{Ni}$ (II) increased from 1.5 to $2.4 \%$. The decrease in the extraction of $\mathrm{Co}$ (II) by ALiCY in the presence of TBP at this $\mathrm{HCl}$ concentration could be attributed to the interaction between the $\mathrm{R}_{4} \mathrm{~N}^{+}$and the polar $\mathrm{P}=\mathrm{O}$ groups of the TBP. This interaction may compete with the interaction between $\mathrm{R}_{4} \mathrm{~N}^{+}$and anionic cobalt complexes, leading to a decrease in $\mathrm{Co}$ (II) extraction as TBP concentration increased.

The anion of Cyanex 272, $\mathrm{A}^{-}$, acts as a base and thus can extract hydrogen ions from aqueous solution, resulting in a 
Table 4. Separation factor (SF) between $\mathrm{Co}(\mathrm{II})$ and $\mathrm{Ni}$ (II) in $\mathrm{HCl}$ solutions extracted by the mixture of ALiCY and TBP

\begin{tabular}{ccccc}
\hline $\begin{array}{c}\text { The concentration of TBP in } \\
\text { the mixture }\left(\mathrm{mol} \cdot \mathrm{L}^{-1}\right)\end{array}$ & 0.02 & 0.05 & 0.10 & 0.20 \\
\hline $\mathrm{SF}_{\mathrm{co} / \mathrm{Ni}}$ at $\mathrm{pH}=4$ & 2.7 & 2.3 & 2.5 & 2.1 \\
\hline $\mathrm{SF}_{\mathrm{Co} / \mathrm{Ni}}$ at $[\mathrm{HCl}]=6.8 \mathrm{~mol} \cdot \mathrm{L}^{-1}$ & 39.3 & 56.0 & 26.7 & 28.3 \\
\hline
\end{tabular}

decrease in the equilibrium concentration of hydrogen ions at both $\mathrm{HCl}$ concentrations, as shown in Table 3. The HA molecules extracted into the organic phase could interact with TBP through hydrogen bonds [35]. A small extraction of $\mathrm{Ni}(\mathrm{II})$ from the $6.8 \mathrm{~mol} \cdot \mathrm{L}^{-1} \mathrm{HCl}$ solution might be ascribed to the fact that TBP can extract electrically neutral $\mathrm{Ni}$ (II) species under this condition.

The solvent extraction of $\mathrm{Co}(\mathrm{II})$ and $\mathrm{Ni}(\mathrm{II})$ by mixtures of ALiCY and TBP can be proposed as

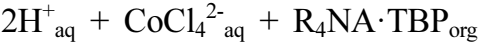

$$
\begin{aligned}
& =\mathrm{R}_{4} \mathrm{NHCoCl}_{4 \text { org }}+\mathrm{HA}_{\text {org }} \cdot \mathrm{TBP}_{\text {org }} \\
& \mathrm{H}^{+}{ }_{\text {aq }}+\mathrm{CoCl}_{3}{ }^{-}{ }_{\text {aq }}+\mathrm{R}_{4} \mathrm{NA} \cdot \mathrm{TBP}_{\text {org }} \\
& =\mathrm{R}_{4} \mathrm{NCoCl}_{3 \text { org }}+\mathrm{HA}_{\text {org }} \cdot \mathrm{TBP}_{\text {org }} \\
& \mathrm{NiCl}_{2 \text { aq }}+2 \mathrm{TBP}_{\text {org }}=\mathrm{NiCl}_{2} \cdot(\mathrm{TBP})_{2 \text { org }}
\end{aligned}
$$

On the other hand, in the strong acid medium $\mathrm{Co}$ (II) ions were selectively extracted over $\mathrm{Ni}(\mathrm{II})$ by the mixture of ALiCY and TBP, which was not observed for the weak case. This can be confirmed by comparing the separation factors of $\mathrm{Co}(\mathrm{II})$ and $\mathrm{Ni}(\mathrm{II})$ for each $\mathrm{HCl}$ solution (see in Table 4). However, when TBP concentration was increased in the mixture, it led to a decrease in the separation factor between the two metals in the strong acid medium, because the extraction percentage of $\mathrm{Co}$ (II) decreased. The addition of TBP to ALiCY affected the extraction of $\mathrm{Co}(\mathrm{II})$ and $\mathrm{Ni}$ (II) and the effect was more pronounced in the stronger $\mathrm{HCl}$ solution.

The interaction between ALiCY and TBP was further elucidated by the FT-IR and UV/VIS analyses.

3.4 Analysis of the interaction between ALiCY and TBP by FT-IR before and after the extraction of $\mathrm{Co}$ (II) and $\mathrm{Ni}$ (II)

3.4.1 FT-IR of the mixtures of ALiCY and TBP before extraction

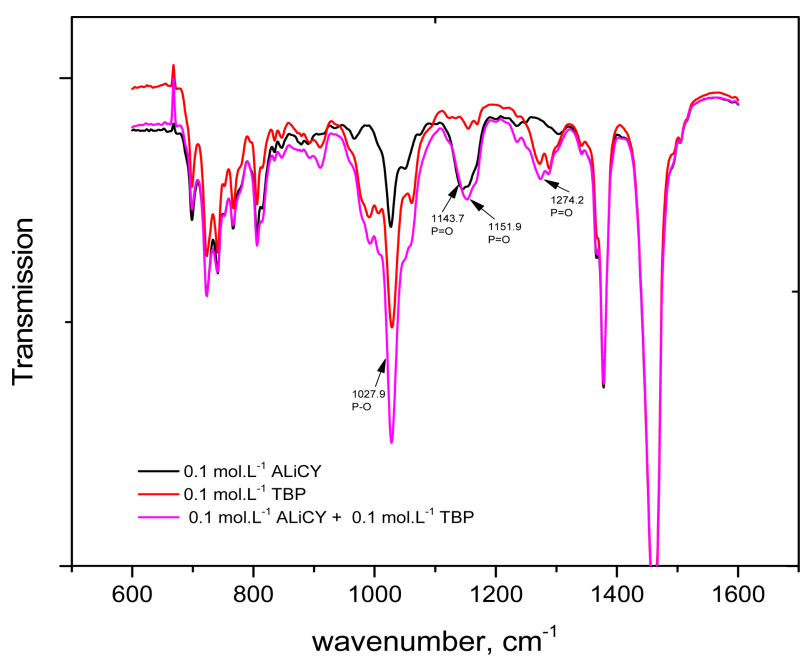

Fig. 4. FT-IR of TBP, ALiCY and the mixture of ALiCY and TBP in kerosene.

Table 5. Frequencies of characteristic vibrational bands of individual extractants in kerosene. (Concentrations of extractants were fixed $\left.0.1 \mathrm{~mol} \cdot \mathrm{L}^{-1}\right)$.

\begin{tabular}{ccc}
\hline Extractants & $\mathrm{P}=\mathrm{O}$ & $\mathrm{P}-\mathrm{O}-\mathrm{H}$ or P-O \\
\hline ALiCY & 1143.7 & 1027.9 \\
\hline TPB & 1027.9 & 1274.2 \\
\hline ALiCY - TBP & 1151.9 & 1274.2 \\
\hline
\end{tabular}

TBP contains polar functional groups of high nucleophilicity $-\mathrm{P}=\mathrm{O}$, which could be responsible for the interaction with other molecules. The characteristic bands observed in the spectra of organophosphorous acid esters result from $\mathrm{P}=\mathrm{O}$ and $\mathrm{P}-\mathrm{O}-\mathrm{C}$ stretching vibrations. Aliphatic phosphine oxides absorb in the $1150-1100 \mathrm{~cm}^{-1}$ region and the phosphate esters absorb in the $1299-1250 \mathrm{~cm}^{-1}$ region [36]. Thus, the FT-IR spectrum in the $1600-600 \mathrm{~cm}^{-1}$ region should be useful in identifying the possible interactions between TBP and ALiCY.

The FT-IR spectra of ALiCY, TBP and their mixture at equimolar ratios were analyzed. The concentration of all the extractants was fixed at $0.1 \mathrm{~mol} \cdot \mathrm{L}^{-1}$. The spectra data are presented in Fig. 4 and Table 5. The results in Fig. 4 show that shifts in peak position did not occur when single extractants were mixed with each other, except for a slight shift in the peak of the $\mathrm{P}=\mathrm{O}$ groups from $1143.7 \mathrm{~cm}^{-1}$ to $1151.9 \mathrm{~cm}^{-1}$. Such changes may be ascribed to the formation of hydrogen bonding by dipole-dipole attraction between the $\mathrm{P}=\mathrm{O}$ groups of TBP, and the hydrogen atoms in the methyl 


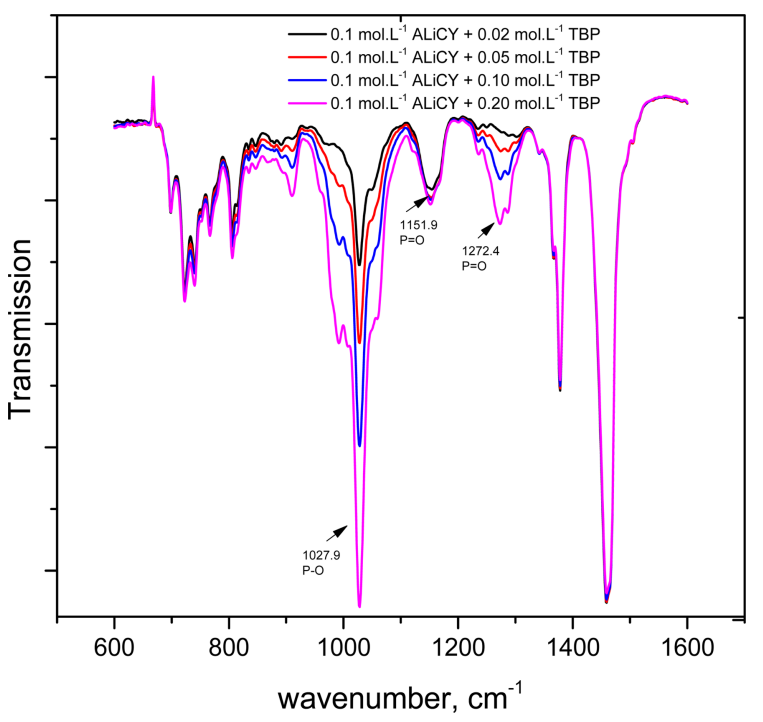

Fig. 5. FT-IR of the mixture of $0.1 \mathrm{~mol} \cdot \mathrm{L}^{-1} \mathrm{ALiCY}$ and various concentration of TBP (from 0.02 to $0.2 \mathrm{~mol} \cdot \mathrm{L}^{-1}$ ) in kerosene.

group of the $\mathrm{R}_{4} \mathrm{~N}^{+}$ions, which affects the electrostatic interaction between $\mathrm{R}_{4} \mathrm{~N}^{+}$and $\mathrm{A}^{-}$ion pairs. This led to a shift in the $\mathrm{P}=\mathrm{O}$ band of the $\mathrm{A}^{-}$anion in the mixture. It might be said that the interaction between ALiCY and TPB was not strong enough to lead to a shift in other peaks.

The effect of TBP concentration on the interaction was also considered by changing the concentration from 0.02 to 0.2 $\mathrm{mol} \cdot \mathrm{L}^{-1}$ in the mixture (Fig. 5). As TBP concentration increased in the mixture with $\mathrm{ALiCY}$, an increase in the intensity of peaks at $1027.9 \mathrm{~cm}^{-1}$ (P-O group) and $1271 \mathrm{~cm}^{-1}$ $(\mathrm{P}=\mathrm{O}$ group $)$ was observed. However, there was no change in the intensity of the peak of the $\mathrm{P}=\mathrm{O}$ group of the $\mathrm{A}^{-}$anion at $1151.9 \mathrm{~cm}^{-1}$. This also further supports the above comments about the weak interaction between ALiCY and TBP.

\subsubsection{FT-IR of the mixtures of ALiCY and TBP} after extraction at several $\mathrm{HCl}$ concentrations

The organic phases after extraction in the $1.0 \times 10^{-4} \mathrm{~mol} \cdot \mathrm{L}^{-1}$ $\mathrm{HCl}$ were analyzed by FT-IR. The spectral data in Fig. 6 indicates that the shift in the characteristic peaks of $\mathrm{P}=\mathrm{O}$ (at $1151.9 \mathrm{~cm}^{-1}$ ) and the $\mathrm{P}=\mathrm{O}$ (at $1272.4 \mathrm{~cm}^{-1}$ ) groups did not occur in the TBP concentration range, meaning there was little difference in the FT-IR of the organic phase between before and after extraction (see Fig. 5). This shows that the extraction of $\mathrm{Co}(\mathrm{II})$ and $\mathrm{Ni}$ (II) from a weak acidic medium did not affect the interaction between the mixtures. The

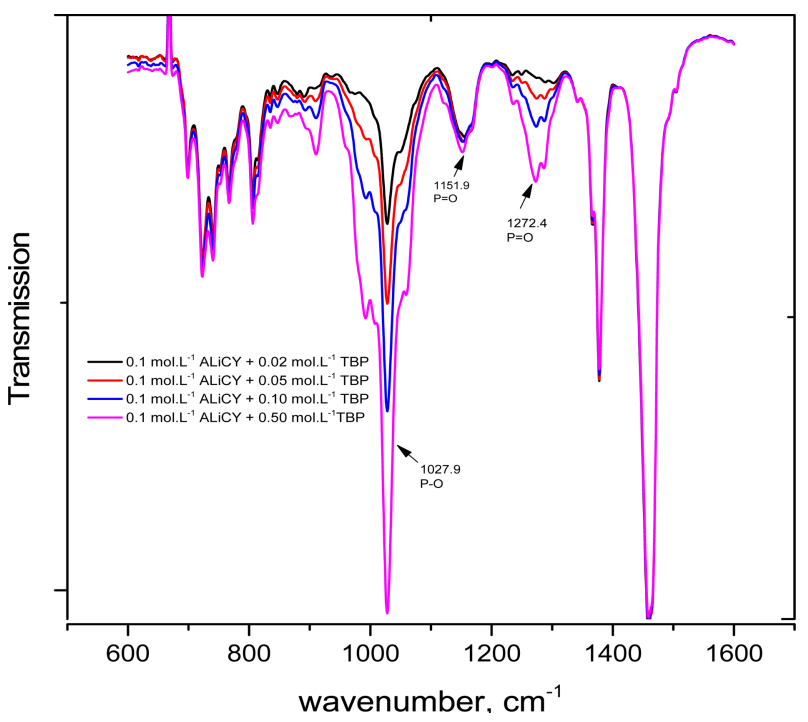

Fig. 6. FT-IR spectra of loaded organic phase after extraction from $\mathrm{Co}(\mathrm{II})$ and $\mathrm{Ni}$ (II) solution at $1.0 \times 10^{-4} \mathrm{~mol} \cdot \mathrm{L}^{-1}$

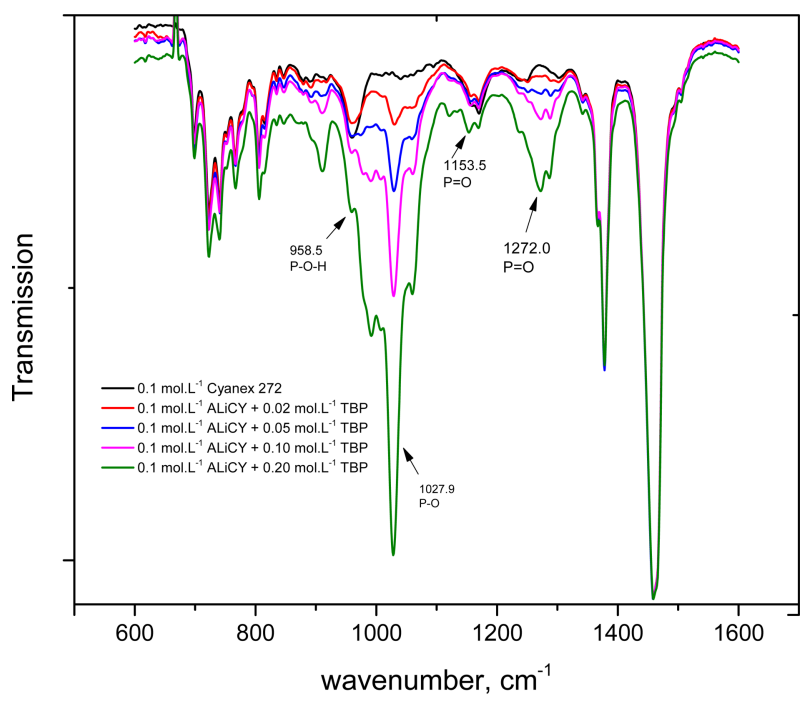

Fig. 7. FT-IR spectra of organic phase after extraction from Co(II) and $\mathrm{Ni}(\mathrm{II})$ solution at $6.8 \mathrm{~mol} \cdot \mathrm{L}^{-1} \mathrm{HCl}$

results agree well with the proposed reaction (Eq. 5) which describes the role of Cynex 272 anions during the extraction of $\mathrm{Co}(\mathrm{II})$ and $\mathrm{Ni}$ (II) from a weak acid medium.

Fig. 7 shows the spectra of the mixtures after the extraction of $\mathrm{Co}$ (II) and $\mathrm{Ni}$ (II) from the $6.8 \mathrm{~mol} \cdot \mathrm{L}^{-1} \mathrm{HCl}$ solution. The peak of the P-O-H groups reappeared at $958.5 \mathrm{~cm}^{-1}$, similar to that of Cyanex272. This indicated that $\mathrm{A}^{-}$ions in the mixture reacted with hydrogen ions in the aqueous phase to form HA, namely, the P-O-H group. In addition, a change in the peaks of the $\mathrm{P}-\mathrm{O}-\mathrm{H}$ groups and $\mathrm{P}=\mathrm{O}$ groups (at 1153.5 


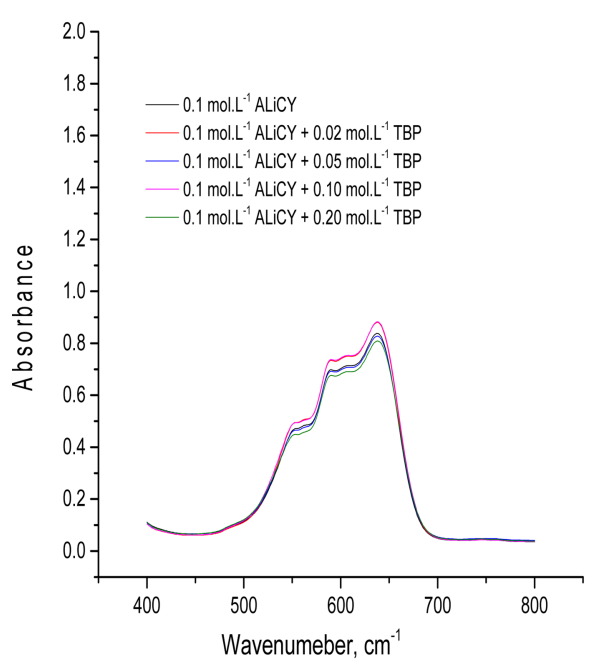

(a)

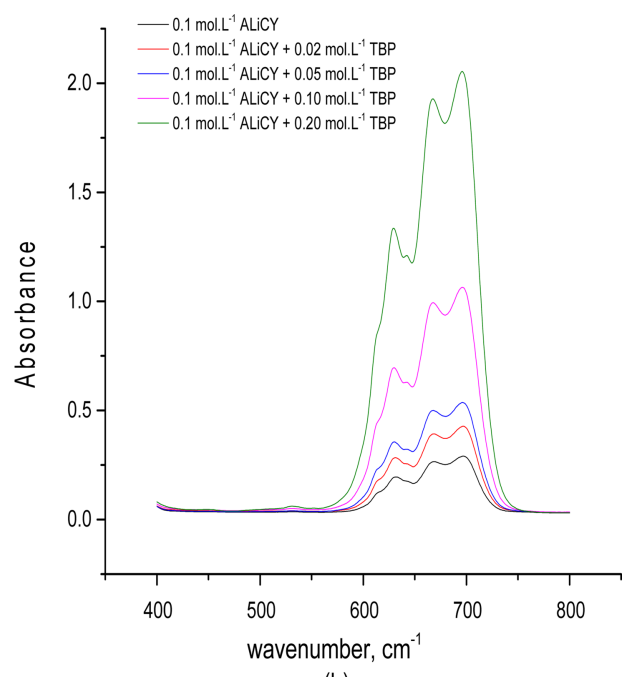

(b)

Fig. 8. UV/VIS spectra of organic phase after extraction with aqueous phase at $1 \times 10^{-4} \mathrm{~mol} \cdot \mathrm{L}^{-1}$ (a) and $6.8 \mathrm{~mol} \cdot \mathrm{L}^{-1}(\mathrm{~b})$

$\mathrm{cm}^{-1}$ ) of the Cyanex272 anion, and in the peaks of the $\mathrm{P}=\mathrm{O}$ groups (at $1272.0 \mathrm{~cm}^{-1}$ ) of TBP were observed. This indicates that the interaction between HA and TBP occurs through hydrogen bonding. Compared to the spectra of Cyanex272, the bonds in the mixture were not clear. These FT-IR data support the occurrence of Eqs. (6) and (7), indicating that the extraction behavior of the mixture of ALi-D2 and TBP considerably depends on interaction between the $\mathrm{R}_{4} \mathrm{~N}^{+}$ cations and meal ions. Competition between the metal complex ions and TBP molecules in the interaction with $\mathrm{R}_{4} \mathrm{~N}^{+}$cations could explain the decrease in the extraction percentage of $\mathrm{Co}$ (II) when the concentration of TBP in the mixture was increased.

\subsection{UV/VIS Spectra Analysis}

The coordination of $\mathrm{Ni}(\mathrm{II})$ and $\mathrm{Co}(\mathrm{II})$ complexes formed in the presence of chloride ions can be determined by UV/Vis spectra of the organic phase. It was reported that the $\mathrm{Ni}(\mathrm{II})$ complexes appear with two bands between 600 and $800 \mathrm{~cm}^{-1}$ for the octahedral configurations (e.g., $\left[\mathrm{Ni}\left(\mathrm{H}_{2} \mathrm{O}\right)_{6}\right]^{2+}$ and $\left.\left[\mathrm{Ni}\left(\mathrm{H}_{2} \mathrm{O}\right)_{5} \mathrm{Cl}\right]^{+}\right)$and double bands at $650-750 \mathrm{~cm}^{-1}$ for $\mathrm{NiCl}_{4}{ }^{-}$in trioctylamine chloride after extraction by Cyphos 101 and Cyphos 104 [13, 37, 38]. In Fig. 8 a), the UV/Vis confirmed that peaks between 590 and $640 \mathrm{~cm}^{-1}$ correspond to $\mathrm{Ni}(\mathrm{II})$ octahedral complexes and no peaks were observed for $\mathrm{NiCl}_{4}{ }^{2-}$ in the organic phase. Therefore, this agrees well with the extraction data, that the percentage of $\mathrm{Ni}(\mathrm{II})$ extraction was negligible at this condition. As TBP concentration increased in the mixtures, there was no observed difference in the absorbance of the mixtures, indicating that TBP did not affect the extraction of Co(II) and $\mathrm{Ni}(\mathrm{II})$. These results also agree well with the results in Fig. 6.

The spectra in Fig. 8a and Fig. 8b show a shift in the configuration of the $\mathrm{Co}$ (II) complex, from octahedral (peak at $550 \mathrm{~nm})$ to tetrahedral $(700 \mathrm{~nm}$, broad signal), as $\mathrm{HCl}$ concentration varied from $1.0 \times 10^{-4}$ to $6.8 \mathrm{~mol} \cdot \mathrm{L}^{-1}$. The predominant extracted species of $\mathrm{Co}(\mathrm{II})$ in the organic phase was $\mathrm{CoCl}_{4}{ }^{2-}[13,38]$. FT-IR and UV/VIS data supports that Eqs. (3) and (4) are responsible for the extraction of $\mathrm{Co}(\mathrm{II})$ from $6.8 \mathrm{~mol} \cdot \mathrm{L}^{-1} \mathrm{HCl}$ solution. On the other hand, no $\mathrm{Ni}(\mathrm{II})$ complexes were observed under this experimental condition, indicating that $\mathrm{Ni}(\mathrm{II})$ was not extracted from the $6.8 \mathrm{~mol} \cdot \mathrm{L}^{-1}$ $\mathrm{HCl}$ solution.

\section{Conclusions}

The extraction of $\mathrm{Co}$ (II) and $\mathrm{Ni}$ (II) from two $\mathrm{HCl}$ concentrations $\left(1.0 \times 10^{-4}\right.$ and $\left.6.8 \mathrm{~mol} \cdot \mathrm{L}^{-1}\right)$ was investigated by employing an ionic liquid (ALiCY) and its mixture with TBP. In the extraction with ALiCY, both $\mathrm{Co}$ (II) and $\mathrm{Ni}(\mathrm{II})$ were extracted from the $1.0 \times 10^{-4} \mathrm{~mol} \cdot \mathrm{L}^{-1} \mathrm{HCl}$, while only $\mathrm{Co}$ (II) was extracted from the $6.8 \mathrm{~mol} \cdot \mathrm{L}^{-1} \mathrm{HCl}$, and thus separation of the two metal ions was possible. These extraction data indicate that ALiCY acts as a cation 
extractant in a weak $\mathrm{HCl}$ solution but an anion extractant in a concentrated $\mathrm{HCl}$ solution. The advantage of employing ALiCY over single Cyanex272 lies in its ability to extract hydrogen ions from the aqueous, which is of great importance in controlling the equilibrium $\mathrm{pH}$.

The effect of adding TBP to ALiCY on the extraction of the two metal ions was found to depend on $\mathrm{HCl}$ concentration. The addition of TBP to ALiCY resulted in a decrease in the extraction percentage of $\mathrm{Co}$ (II) from the 6.8 $\mathrm{mol} \cdot \mathrm{L}^{-1} \mathrm{HCl}$ solution, while its effect was negligible from the $1.0 \times 10^{-4} \mathrm{~mol} \cdot \mathrm{L}^{-1} \mathrm{HCl}$. FT-IR data showed that solvation of $\mathrm{R}_{4} \mathrm{~N}^{+}$by the TBP molecules was responsible for the decrease in the extraction of $\mathrm{Co}$ (II) from the $6.8 \mathrm{~mol} \cdot \mathrm{L}^{-1} \mathrm{HCl}$. In addition, the hydrogen bond between TBP and Cyanex 272 was also observed. The TBP effect in the $1.0 \times 10^{-4} \mathrm{~mol} \cdot \mathrm{L}^{-1}$ $\mathrm{HCl}$ was attributed to the weak interaction between the anion of Cyanex 272 and TBP. UV/VIS spectra in loaded organic showed that a tetrahedral $\mathrm{Co}$ (II) chloride complex was extracted from the $6.8 \mathrm{~mol} \cdot \mathrm{L}^{-1} \mathrm{HCl}$ solution, while hexahedral $\mathrm{Ni}(\mathrm{II})$ was extracted from the $1.0 \times 10^{-4} \mathrm{~mol} \cdot \mathrm{L}^{-1}$ $\mathrm{HCl}$.

\section{ACKNOWLEDGMENTS}

This study was supported by a grant from the Korean Research Foundation (2018R1D1A1BO7044951)

\section{REFERENCES}

1. J. Rydberg, M. Cox, C. Musikas, and G. R. Chppin, Solvent Extraction Principles and Practice, Marcel Dekker: New York, 2004

2. B. Jakovljevic, C. Bourget, and D. Nucciarone, Hydrometallurgy 75, 25 (2004).

3. G. M. Ritcey, Tsinghua Sci. Technol. 11, 137 (2006).

4. Z. Zhu, Y. Pranolo, W. Zhang, and C. Y. Cheng, J. Chem. Technol. Biotechnol. 86, 75 (2010).

5. K. Sarangi, B. R. Reddy, and R. P. Das Hydrometallurgy 52, 253 (1999).

6. Y. Liu, J. Chen, and D. Li, Sep. Sci. Technol. 47, 223 (2012).

7. C. K. Gupta and N. Krishnamurthy, Extractive metallurgy of rare earths; CRC Press: Boca Raton, FL (2005).

8. J. S Wilkes, Green Chemistry 4, 73 (2002).

9. X. Sun, H. Luo, and S. Dai, Chem. Rev. 112, 100 (2012).
10. V. T. Nguyen, J. Lee, J. Jeong, B. S. Kim, G. Cote, and A. Chagnes, Ind. Eng. Chem. Res. 54, 1350 (2015).

11. J. Castillo, M. T. Coll, A. Fortuny, P. D. Navarro, R. Sepulveda, and A. M. Sastre, Hydrometallurgy 141, 89 (2014).

12. G. Helle, C. Mariet, and G. Cote, Talanta 139, 123 (2015).

13. P. Rybka and M. Regel-Rosocka, Sep. Sci. Technol. 47, 1296 (2012).

14. M. Regle-Rosocka and M. Wisniewki, Ionic Liquids in Separation of Metal Ions from Aqueous Solution, in: Scott T. Handy (Eds), Applications of Ionic Liquids in Science and Technology, pp. 375-398, InTech, Croatia (2011).

15. A. E. Visser, R. P. Swatloski, W. M. Reichert, S. T. Griffin, and R. D Rogers, Ind. Eng. Chem. Res. 39, 3596 (2000).

16. A. E. Visser and R. D. Rogers, J. Solid State Chem. 171, 109 (2003).

17. J. P. Mikkola, P. Virtanen, and R. Sjoholm, Green Chemistry 8, 250 (2006).

18. S. Wellens, B. Thijs, and K. Binnemans, Green Chemistry 14, 1657 (2012).

19. X. Sun, Y. Ji, F. Hu, B. He, J. Chen, and D. Li, Talanta 81 , 1877 (2010).

20. V. M. Egorov, D. I. Djigailo, D. S. Momotenko, D. V. Chernyshov, I. I. Torochesnikova, S. V. Smirnova, and I. V. Pletnev, Talanta 80, 1177 (2010).

21. E. Padhan and K. Sarangi, Hydrometallurgy 167, 134 (2017).

22. P. Rybka and M. Regel-Rosocka, Sep. Sci. Technol. 47, 1296 (2012).

23. C. G. Oh and M. S. Lee, Korean J. Met. Mater. 56, 870 (2018).

24. T. T. Tuan, M. Iqbal, and M. S. Lee, Korean J. Met. Mater. 57, 787 (2019)

25. M. N. Le, S. H. Son, \& M. S. Lee, Korean J. Met. Mater. 57, 1 (2019).

26. L. Y. Wang and M. S. Lee, J. Mol. Liq. 240, 345 (2017).

27. M. Irannajad, Z. Afzali, and H. K. Haghighi, Russ. J. NonFerr. Met. 59, 605 (2018).

28. B. Pospiech, Sep. Sci. Technol. 49, 1706 (2014).

29. A. Fortuny, M. T. Coll, and A. M. Sastre, Sep. Purif. Technol. 97, 137 (2012).

30. A. I. Vogel, Textbook of Quantitative Chemical analysis, $5^{\text {th }}$, pp 295-296, Longman scientific \& Technical, New York, (1989).

31. J. Saji, K. S. John, and M. L. P. Reddy, Solvent Extr. Ion Exc. 18, 877 (2000). 
32. Y. Liu and M. S. Lee, Solvent Extr. Ion Exc. 34, 74 (2015).

33. A. H. Blitz-Raith, R. Paimin, R. W.Cattrall, and S. D. Kolev, Talanta 71, 419 (2007).

34. S. Kagaya, R. W. Cattrall, and S. D. Kolev, Anal. Sci. 27, 653 (2011).

35. B. Gajda and M. B. Bogacki, Physicochem. Probl. Mi. 41, 145 (2007).
36. K. Staszak and K. Prochaska, Hydrometallurgy 90, 75 (2008).

37. S. Lindenbaum and G. E. Boyd, J. Phys. Chem. 67, 1238 (1963).

38. M. Magini, G. Paschina, and G. Piccaluga, J. Chem. Phys. 76, 1116 (1982). 